\title{
Gyrodactylus pisculentus sp. n. (Monogenoidea: Gyrodactylidae) associated with mortality of the northern pipefish, Syngnathus fuscus (Syngnathiformes: Syngnathidae) at the Woods Hole Science Aquarium
}

\author{
Sea Rogers Williams ${ }^{1,3}$, Delane C. Kritsky ${ }^{2}$, Bridget Dunnigan $^{1}$, Rebecca Lash $^{1}$ and Peter Klein ${ }^{1}$ \\ ${ }^{1}$ NOAA Fisheries Service, Northeast Fisheries Science Center, Woods Hole Science Aquarium, 166 Water Street, Woods Hole, \\ MA 20543, USA; \\ ${ }^{2}$ Department of Health and Nutrition Sciences, College of Health Professions, Box 8090, Idaho State University, Pocatello, \\ ID 83209, USA; \\ ${ }^{3}$ Current address: National Marine Life Center, 120 Main Street, Buzzards Bay, MA 02532-0269, USA
}

Key words: Monogenoidea, Gyrodactylidae, Gyrodactylus pisculentus, Syngnathus fuscus, Woods Hole Science Aquarium

\begin{abstract}
Gyrodactylus pisculentus sp. n. is described from the head, body and fins of the northern pipefish, Syngnathus fuscus Storer (Syngnathidae) from the environs of Woods Hole, Massachusetts, USA. The new species is compared with Gyrodactylus shorti and Gyrodactylus syngnathi, species previously recorded from pipefish in the United States and Norway, respectively. Gyrodactylus pisculentus was frequently associated with mortality of northern pipefish held in quarantine at the Woods Hole Science Aquarium during 2002-2005. The clinical account of the infections and treatment protocols are presented.
\end{abstract}

The northern pipefish, Syngnathus fuscus Storer, is a common inhabitant of bays and estuaries of the eastern coasts of the United States and Canada (Robins and Ray 1986) and has traditionally been collected for display at the Woods Hole Science Aquarium. During standard 30day quarantine, mortality of pipefish frequently coincided with a high infection of an undescribed species of Gyrodactylus von Nordmann, 1832 (Monogenoidea). Although Greenwell (2002) indicated that monogenoids do not occur on syngnathids, two species of Gyrodactylus, G. shorti Hollimann, 1963 from the gulf pipefish, Syngnathus scovelli (Evermann et Kendall), and G. syngnathi Appleby, 1996 from Nilsson's pipefish, S. rostellatus Nilsson, have been described from the United States and Norway, respectively. Two additional reports establish presence of unidentified monogenoids on the bay pipefish, S. griseolineatus Ayres (now S. leptorhynchus Girard), by Arai (1969) as Gyrodactyloidea and on the wide-bodied pipefish, Stigmatopora nigra Kaup, by Ernst et al. (2001) as Anacanthocotyle sp. 1. The clinical significance of these infections has not been previously reported. In the present paper, the new species of Gyrodactylus is described, and the clinical affects of the infection on the northern pipefish in quarantine and treatment protocols are presented.

\section{MATERIALS AND METHODS}

Northern pipefish were caught by seine or dip net from beds of eel grass (Zostera marina) in marine waters near
Woods Hole, Massachusetts, during June and October of 2002-2005. Pipefish were quarantined for 30 days in 10-120litre flow-through isolation tanks fed from the Woods Hole Science Aquarium's temperate water reservoir at typical flow rates of 1-2 1/min before introduction to the display aquariums. Water temperature in the tanks was maintained between 21 and $26^{\circ} \mathrm{C}$; salinity ranged from 29.4 to $31.7 \mathrm{ppt}$ and $\mathrm{pH}$ between 7.6 and 8.0; dissolved oxygen was 5.0 to 6.27 $\mathrm{mg} / \mathrm{l}$. Fish were fed thawed mysids and bloodworms. The fish were peri-odically inspected for gyrodactylids by skin scrape with a plastic cover slip swept across the body in one or two motions; mucus samples were then examined for gyrodactylids using a stereomicroscope. Collections of adequate mucus samples by this method were hampered due to the host's delicate nature, small size and uneven skin surface; small fish $(<5 \mathrm{~cm})$ were not subjected to routine skin scrapes as mortality of these fish would often occur following the procedure. Two or more of the larger fish from each tank were examined by skin scrape two to five times a week.

Helminths from a single pipefish were used for identification and description of the new gyrodactylid species. This host was placed in $5-10 \%$ formalin and shaken vigorously to dislodge the parasites. Gyrodactylids were subsequently removed from the sediment with a fine probe and stereomicroscope. Some specimens were mounted unstained in Gray and Wess medium for study of sclerotized structures; other specimens were stained with Gomori's trichrome or Grenacher borax carmine and mounted as whole mounts in Canada balsam for study of soft anatomy (Kritsky et al. 1978, Humason 1979). Measurements, all in micrometres, represent straight-line distances between extreme points and are expressed as the mean followed by the range and number (n) of structures measured

Address for correspondence: D.C. Kritsky, Campus Box 8090, Idaho State University, Pocatello, Idaho 83209, USA. Phone: +1 208 282 3726; Fax: +1 208282 4645; E-mail: kritdela@isu.edu 
in parentheses; body length includes that of the haptor. Illustrations were prepared with the aid of a camera lucida or microprojector. Terminology was that of Mizelle and Kritsky (1967) and Kritsky and Mizelle (1968). Type specimens were deposited in the United States National Parasite Collection (USNPC), Beltsville, Maryland, USA; the Natural History Museum (BMNH), London, UK; and the helminth collection (IPCAS) of the Institute of Parasitology, Academy of Sciences of the Czech Republic, České Budějovice, Czech Republic. For comparative purposes, the following museum specimens were examined: holotype, 3 paratypes, Gyrodactylus shorti Holliman, 1963 (USNPC 59597); paratype, Gyrodactylus syngnathi Appleby, 1996 (BMNH 1995.9.7.2-4).

\section{RESULTS}

Class: Monogenoidea Bychowsky, 1937

Subclass: Polyonchoinea Bychowsky, 1937

Order: Gyrodactylidea Bychowsky, 1937

G y r o d a c t y li d a e Van Beneden et Hess, 1863

\section{Gyrodactylus pisculentus sp. $\mathrm{n}$.}

Figs. $1-5$

Description. Body fusiform, robust, 335 (249-407; $\mathrm{n}=23)$ long; greatest width $99(75-126 ; \mathrm{n}=25)$ at level of uterus; peduncle directed ventrally from trunk at about an $80-90^{\circ}$ angle; haptor opening ventrally. Cephalic lobes frequently contracted, each containing a head organ and spike sensilla. Bilateral cephalic glands unicellular, posterolateral to pharynx. Pharynx with two tandem bulbs; posterior bulb $53(48-58 ; \mathrm{n}=25)$ wide; anterior bulb $34(31-40 ; n=25)$ wide, with 8 papillae. Oesophagus short to nonexistent; intestinal caeca nonconfluent posterior to gonads, with thick wall. Testis 33 (24-37; $n=9)$ long, $26(23-33 ; n=9)$ wide, subovate, lying posterodorsal to germarium; vas deferens not observed; seminal vesicle subspherical; 2 bilateral prostatic glands, each emptying into male copulatory organ (MCO) by short prostatic duct; $\mathrm{MCO}$ a subspherical bulb $13(10-15 ; \mathrm{n}=14)$ in diameter, armed with distal spine, 2 bilateral large spinelets and 7-9 smaller medial spinelets. Germarium $27(22-32 ; \mathrm{n}=12)$ long, 31 (23$39 ; \mathrm{n}=12$ ) wide, usually containing large oocyte surrounded by thin peripheral layer of germinal cells; uterus with 1 or 2 generations of embryos (or empty); uterine pore midventral at level of seminal vesicle. Vitellarium absent, replaced by apparently syncytial masses located in posterior trunk. Haptor subcircular in outline, 67 (52-72; n = 24) long, 65 (58-70; $\mathrm{n}=23$ ) wide. Hooks similar, marginal, intrahamular; each 25 $(21-28 ; \mathrm{n}=13)$ long (including hooklet and shank); shank uniform in diameter; hooklet $7(6-8 ; n=26)$ long, with delicate somewhat closed point extending noticeably past tip of toe, heavy shaft, truncate heel, and toe with short shelf and sloped tip; filamentous hook (FH) loop about one-half shank length. Anchor 41 (37-43; $n=26)$ long, robust, having short superficial root with tip bent medially, anchor fold securing ends of superficial bar, slightly curved shaft and strongly recurved tapered point. Superficial bar 14 (13-16; n = 17) long, plate-like, subtrapezoidal, with delicate short posterior shield; deep bar $12(10-14 ; \mathrm{n}=16)$ long, variable, usually with medial expansion, ends inserted into knobs of anchor base.

$\mathrm{T}$ y p e h o s t: Northern pipefish, Syngnathus fuscus Storer (Syngnathidae).

T y p e 1 o c a l i t y : Environs of Woods Hole, Massachusetts $\left(41^{\circ} 31^{\prime} \mathrm{N}, 70^{\circ} 31^{\prime} \mathrm{W}\right)$; 30 August 2005.

$\mathrm{S}$ it e of infection: Head, body, fins.

S p e c i m e n s s t udied: Holotype (USNPC 100698); 34 paratypes (USNPC 100699; BMNH 2008.4.8.1-10; IPCAS M-469).

E t y $\mathrm{m}$ o 1 o g y : The specific name, an adjective, is from Latin (pisculentus $=$ abounding in fish).

Remarks. Gyrodactylus pisculentus most closely resembles $G$. shorti from the brood pouch of the gulf pipefish. Although the type specimens of $G$. shorti are stained with Semichon's acetocarmine and mounted in Canada balsam and determination of the morphology of the sclerotized structures of the haptor and MCO was marginal, they show that a deep bar is present (absent according to Holliman 1963), that the hooklet point is fine and extends well past the level of the tip of the toe, and that a short delicate shield occurs on the posterior margin of the superficial bar (not depicted by Holliman 1963). Gyrodactylus pisculentus is distinguished from $G$. shorti by having a longer and more robust hooklet point and by having a deep bar with a medial expansion (deep bar uniform in G. shorti). The new species differs from $G$. syngnathi by having the point of the hooklet extending well past the level of the toe (point short in G. syngnathi). Appleby (1996) did not provide a figure of the MCO of $G$. syngnathi, although he states that it is armed with one large spine and 8-11 small spinelets of unequal size in one arched row.

The brood pouch of $S$. fuscus was not examined for gyrodactylids during the present study. While Holliman (1963) states that his specimens of $G$. shorti were from the brood pouch of $S$. scovelli and that he did not find worms on the skin, fins and remaining parts of the body, he indicates that the host specimen was preserved in $10 \%$ formalin for a considerable amount of time prior to examination for gyrodactylids, that many of the worms were distorted and poorly fixed, and that he only used those with a "normal extended appearance" for his description of the species. It is likely, therefore, that worms from other sites on the body of $S$. scovelli had fallen off and were lost during preservation of the host specimen. Thus, the different sites of infection on the host of G. shorti (brood pouch) and of G. pisculentus (body surface) requires additional investigation to determine whether or not site specificity exists between the two species. 

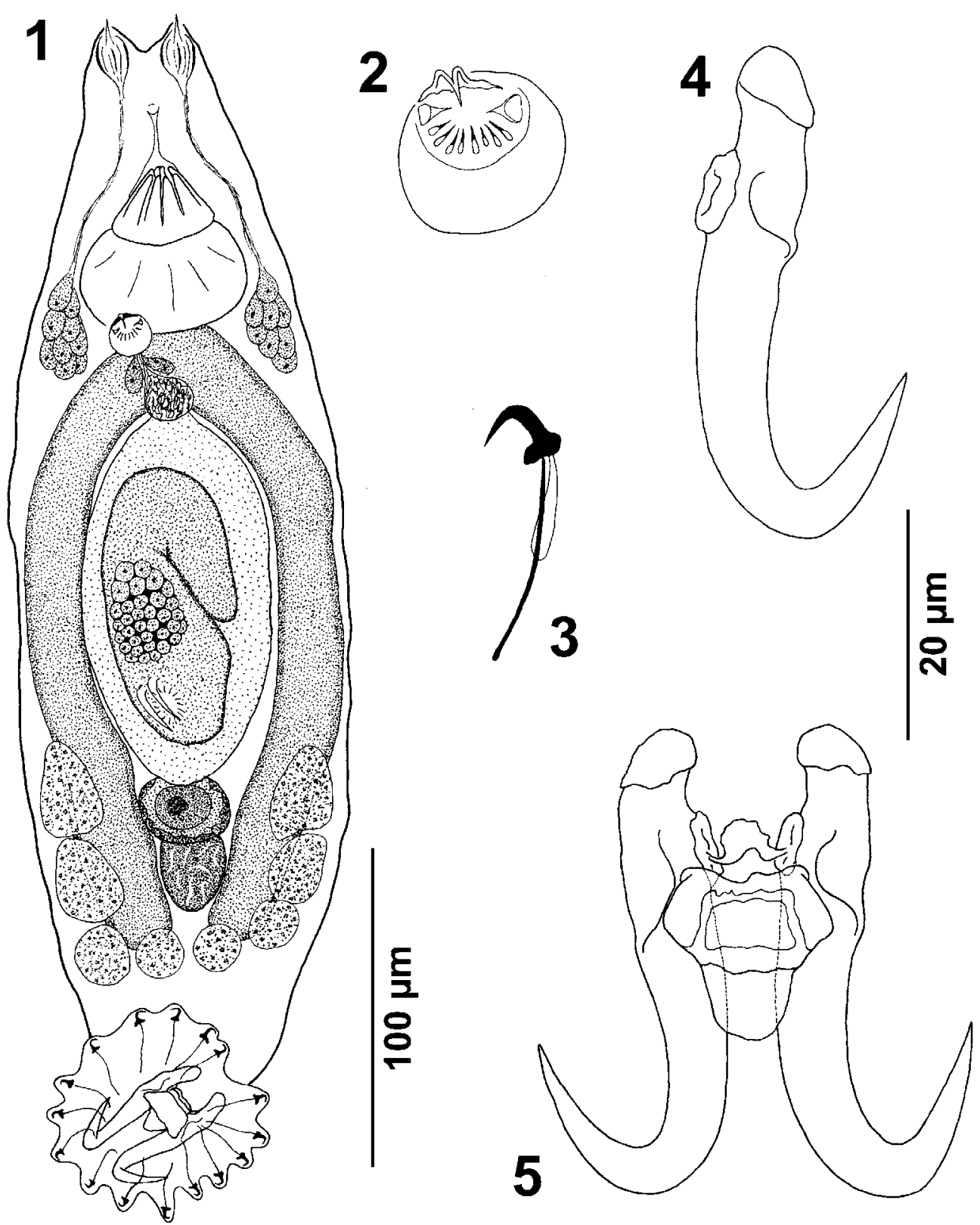

Figs. 1-5. Gyrodactylus pisculentus sp. n. from the northern pipefish, Syngnathus fuscus, from Woods Hole, Massachusetts, USA. Fig. 1. Whole mount (ventral, composite). Fig. 2. Male copulatory organ. Fig. 3. Hook. Fig. 4. Anchor. Fig. 5. Anchor/bar complex (ventral). Scale bars: Fig. $1=100 \mu \mathrm{m}$; Figs. $2-5=20 \mu \mathrm{m}$.

Clinical account. Prevalence and intensity of G. pisculentus were not determined on northern pipefish immediately after capture from the wild. Nonetheless, positive mucus samples from pipefish with up to 93 gyrodactylids per fish were obtained shortly after the fish were delivered from the wild to the aquarium; one pipefish, initially negative by skin scrape, was soon after found to harbour gyrodactylids at necropsy. Gyrodactylids were observed to come into the aquarium in comparatively small numbers on wild pipefish and later developed low to moderately high intensities during quarantine. Mortality of pipefish generally occurred 2 to 3 days into quarantine, at which time gyrodactylids were easily identified at necropsy on the head, body and fins (Fig. 6). At necropsy, more than 600 parasites could be encountered on a single quarantined fish.

Other parasites encountered at necropsy included adults of Opecoeloides vitellosus (Linton) (Digenea) in small numbers in the intestine; at least two different unidentified metacercariae occasionally in the skin and gills; tetraphyllidean plerocercoids in the gut; trypanorhynch plerocercoids of Lacistorhynchus tenuis (von 


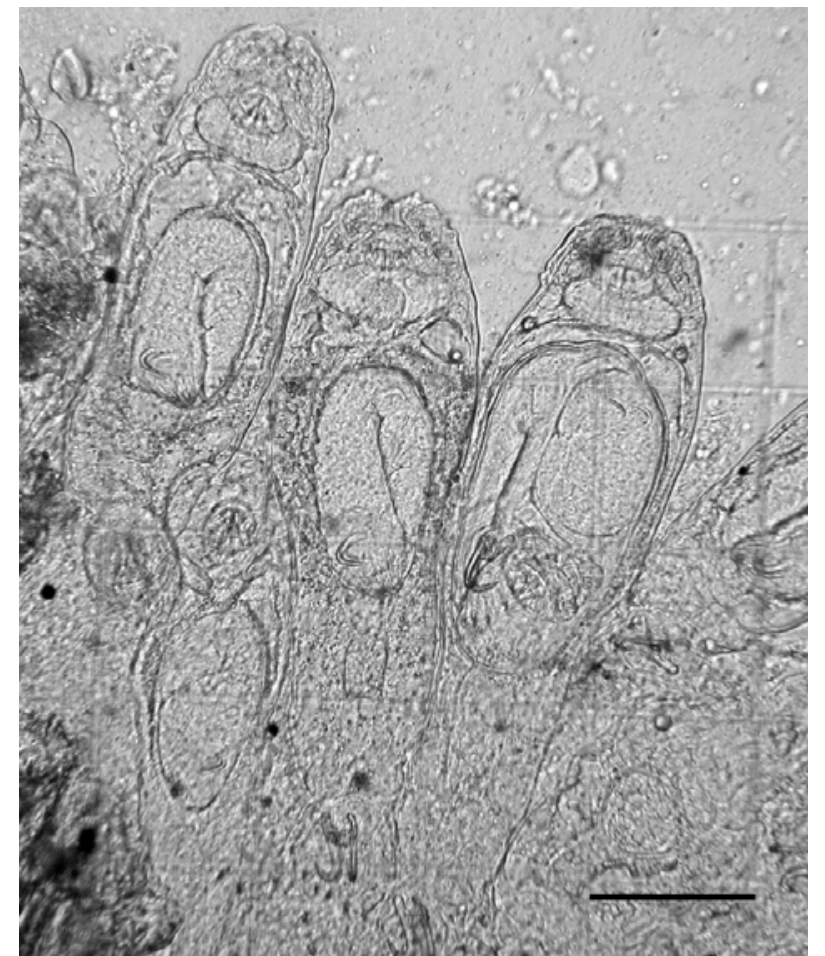

Fig. 6. Photomicrograph of Gyrodactylus pisculentus sp. n. occurring on a fin of the northern pipefish, Syngnathus fuscus. Scale bar $=100 \mu \mathrm{m}$.

Beneden) encysted in the epaxial musculature, and in two separate cases, in the host's swim bladder and cranium, respectively; unidentified larval nematodes occasionally in the intestine; and spores of an unidentified myxozoan free in the lumen of the gall bladder. However, none of these infections caused apparent gross pathology of the respective infected host tissue. Although gyrodactylids were the only significant finding upon necropsy of the host and may have, in part, been responsible for host mortality during quarantine, it is also possible that other parasite burdens, stress from acclimation and water-quality issues may have contributed to the observed mortality.

Transmissions of G. pisculentus from infected to uninfected pipefish appeared to have occurred within the quarantine tanks at the aquarium. Skin-scrapednegative pipefish, isolated within a tank, consistently tested negative for gyrodactylids for more than seven days. However, when a pipefish infected with G. pisculentus was added to the tank but confined to a perforated breeder box, one initially negative fish became positive for gyrodactylids during the following week. Within seven days after the breeder box with the original infected fish was removed, all fish remaining in the tank were positive for gyrodactylids. It is unclear whether the latter infections were a result of transfer of gyrodactylids from the infected fish or developed from existing infections missed on skin-scraped-nega- tive fish. However, this observation suggests that introduction of even one infected pipefish to an aquarium containing otherwise healthy individuals could result in a major episode of gyrodactylosis.

Treatment. In an attempt to eliminate or control gyrodactylids on pipefish, five treatment protocols were attempted. These included exposure of pipefish to one of the following: 1) $4 \mathrm{~min}$ dip in $100 \mathrm{mg} / \mathrm{l}$ praziquantel; 2) $1.5 \mathrm{~h}$ bath in $20 \mathrm{mg} / 1$ praziquantel; 3) $3 \mathrm{~h}$ bath in 9 $\mathrm{mg} / \mathrm{l}$ praziquantel; 4) $1 \mathrm{~h}$ bath in $0.25 \mathrm{ml} / 1$ formalin; and 5) $5 \mathrm{~min}$ dip in dechlorinated (temperature and $\mathrm{pH}$ matched) freshwater. In pipefish with low gyrodactylid intensities, the $1 \mathrm{~h}$ formalin bath repeated 3 times at seven-day intervals cleared infections without significant host mortality. However, when intensities were high, this treatment resulted in as much as $80 \%$ mortality apparently from the treatment protocol, as gyrodactylids were not observed on any of the succumbed pipefish at necropsy. Treatment with $9 \mathrm{mg} / \mathrm{l}$ praziquantel for $3 \mathrm{~h}$ resulted in a significant reduction in gyrodactylid density but was associated with $33 \%$ host mortality. The remaining protocols appeared to be well tolerated by the fish but met with limited to no efficacy in removal of parasites.

\section{DISCUSSION}

While Gyrodactylus pisculentus may or may not have been the primary cause of mortality observed in quarantined pipefish at the Woods Hole Science Aquarium, this report identifies this monogenoid as a potential pathogen of syngnathids in captivity. The direct mode of transmission and lack of an intermediate host coupled with stress associated with capture and captivity provide ideal circumstances for infrapopulations of the gyrodactylid to rapidly increase to comparatively high levels. Although diagnosis of gyrodactylosis on pipefish can be quickly accomplished by skin scrape, the method is not $100 \%$ sensitive and should not be used on small individuals. A $1 \mathrm{~h}$ bath in $0.25 \mathrm{ml} / 1$ formalin repeated three times at seven-day intervals is rec-ommended for mild infections and as a prophylactic treatment. Praziquantel, while less effective, may be better tolerated in debilitated fish with high infection levels and could be utilized as an initial treatment followed by the formalin protocol.

Acknowledgements. The authors wish to thank Dr. A. Dove, Cornell College of Veterinary Medicine, for assistance in the literature search; Teri Frady, George Liles and Rachel Metz, Woods Hole Science Aquarium, for assistance and manuscript review; the many volunteers, docents, and interns at the aquarium that helped with animal care; and Dr. H.W. Palm, Heinrich-Heine-Universität, for identification of Lacistorhynchus tenuis. 


\section{REFERENCES}

APPLEBY C. 1996: Gyrodactylus syngnathi n. sp. (Monogenea: Gyrodactylidae) from the pipefish Syngnathus rostellatus Nilsson, 1855 (Syngnathiformes: Syngnathidae) from the Oslo Fjord, Norway. Syst. Parasitol. 33: 131-134.

ARAI H.P. 1969: Preliminary report on the parasites of certain marine fishes of British Columbia. J. Fish. Res. Board Can. 26: 2319-2337.

ERnst I., WhitTington I.D., JONES M.K. 2001: Diversity of gyrodactylids from some marine fishes in tropical and subtropical Queensland, Australia. Folia Parasitol. 48: 165-168.

GREENWELL M.G. 2002: Syngnathid health management. In: C.D. Bull and J.S. Mitchell (Eds.), Seahorse Husbandry in Public Aquaria. John G. Shedd Aquarium, Chicago, pp. 1317.

HOLLIMAN R.B. 1963: Gyrodactylus shorti, a new species of monogenetic trematode from the brood pouch of the southern pipefish, Syngnathus scovelli (Evermann and Kendall). Tulane Stud. Zool. 10: 83-85.
Humason G.L. 1979: Animal Tissue Techniques, 4th ed. W.H. Freeman and Company, San Francisco, 661 pp.

KRITSKY D.C., LEIBY P.D., KAYTON R.J. 1978: A rapid stain technique for the haptoral bars of Gyrodactylus species (Monogenea). J. Parasitol. 64: 172-174.

KRITSKY D.C., MIZELLE J.D. 1968: Studies on monogenetic trematodes. XXXV. Some new and previously described North American species of Gyrodactylus. Am. Midl. Nat. 79: 205-215.

Mizelle J.D., KRITSKY D.C. 1967: Studies on monogenetic trematodes. XXX. Five new species of Gyrodactylus from the Pacific tomcod, Microgadus proximus (Girard). J. Parasitol. 53: 263-269.

RoBINS C.R., RAY G.C. 1986: A Field Guide to Atlantic Coast Fishes, North America. Houghton Mifflin Company, Boston, 354 pp.

Accepted 9 June 2008 